PLEASE NOTE! THIS IS SELF-ARCHIVED VERSION OF THE ORIGINAL ARTICLE

To cite this Article: P. Palotie, P. Nurkka, S. Juvonen (2017) THE QUALITY MATTERS - THE EXPERIENCES OF A PROJECT MANAGER TRAINING, ICERI2017 Proceedings, pp. 1077-1084.

doi: $10.21125 /$ iceri.2017.0364

URL: https://library.iated.org/view/PALOTIE2017QUA 


\section{THE QUALITY MATTERS-THE EXPERIENCES OF A PROJECT MANAGER TRAINING}

Conference Paper · December 2017

CITATIONS

0

3 authors, including:

\section{Sanna Juvonen}

Laurea Universities of Applied Sciences

3 PUBLICATIONS 1 CITATION

SEE PROFILE

Some of the authors of this publication are also working on these related projects: 


\title{
THE QUALITY MATTERS - THE EXPERIENCES OF A PROJECT MANAGER TRAINING
}

\author{
P. Palotie ${ }^{1}$, P. Nurkka ${ }^{2}$, S. Juvonen ${ }^{2}$ \\ ${ }^{1}$ Valmennuskeskus Public (FINLAND) \\ ${ }^{2}$ Laurea University of Applied Sciences (FINLAND)
}

\begin{abstract}
This paper explores the experiences of a project manager training program developed by Laurea University of Applied Sciences (hereinafter: Laurea UAS), Finland. The training program is meant for professionals at Laurea UAS to increase the competence of project managers who are responsible of externally funded research and development $(R \& D)$ projects. The focus of this research is to highlight the experiences and impact of the training as well as address challenges identified in project managers' work.

Collaboration between higher education institutions and companies, entrepreneurs and funding organizations has gained an increasing importance in R\&D projects from practical, managerial and scientific perspectives. At the moment Laurea UAS is running around 80 externally funded projects and a third of employees at Laurea UAS are in different roles involved in R\&D projects. This has made radical changes to the working culture when compared with the traditional working culture of higher education institutions: complexity and uncertainty has started to play an increasingly big role in projects and project environments. Thus successful organizations need to take care of its employees and their ability to manage chaos, which can be caused by participating different kinds of projects.
\end{abstract}

The purpose of this paper is to describe the experiences and lessons learned at Laurea UAS from its project manager training program. The program was piloted 2016-2017 for around 40 participants representing educated professionals as teachers and project experts to increase their project management competence. Around four participants were interviewed after every training module in order to clarify the efficiency of each module and to figure out how participatory learning methods could help project managers to develop their competence. The total number of research participants was 20.

The research questions were: Which competencies project managers feel they need to learn most? What sort of content in project manager training program would best endorse the development of project management competencies? How participatory learning methods used in training could motivate participants?

The participants of the training program engaged in creating each module by giving their feedback and defining their wishes for the content of the modules. The trainers of the modules used participatory methods and kept the learning atmosphere open for constant reciprocal discussion.

The results of the interviews showed that workplace learning is a complex but fruitful thing to organize. The participants saw that the most important thing in the project manager training program was networking with other colleagues who are involved in the projects as well. Most of them also thought that having constructive dialogues with others helped them to learn and achieve personal learning goals. Based on the research, it can be evaluated that the impact of the training on competence development was remarkable, and the training increased the quality of the project management work at Laurea UAS.

Keywords: Cooperation between Higher Education Institution and Industry, workplace learning, Research, Development and Innovation (RDI), Project Manager Training.

\section{INTRODUCTION}

\subsection{The background of a project work is in pedagogical model}

Cooperation between higher education institutions (HEls) and industrial companies, entrepreneurs and funding organizations has gained increasing importance in R\&D projects from practical, managerial and scientific perspectives [1]. At the moment Laurea UAS is running around 80 externally 
funded projects and a third of employees at Laurea UAS are somehow involved in R\&D projects. This has made radical changes to the working culture when compared with the traditional working culture of higher education institutions. Thomas and Mengel [2] pointed out that complexity, uncertainty and chaos has started to play an increasingly big role in projects and project environments. Thus successful organizations need to take care of its employees and their ability to manage complexity and chaos, which can be caused by participating different kinds of projects.

Laurea University of Applied Sciences is a research and development-oriented organization that produces new competences. To mention some, Laurea UAS specializes in service innovations, focusing on the regional development of Finnish metropolitan area, and offers a multidisciplinary study environment. The working life -oriented pedagogical action model, called Learning by Developing (LbD) offers a different way to learn by studying in authentic development projects together with working life representatives. The LbD model is a pragmatic learning concept where learning is seen as a tool for producing new practices of action through continuous interaction between people and the environment. Collaboration and activities that change individuals and the environment in addition to the role of experiences and interaction are emphasized in the LbD pedagogical action model where learning is active and consists of restructuring and building experiences and handling new situations [3].

Learning by Developing action model has expanded teachers' role as a pedagogue, a regional developer and a researcher and a developer, which can be identified as follows: 1) as preparers and organizers of the LbD implementation process; 2 ) as implementers and as 3) evaluators, mentors and partners for students. [4, 5.]. According to Ahonen, Meristö, Ranta \& Tuohimaa [6], project might consist of different roles: the project coordinator's role might be related to administrative tasks and monitoring; e.g. budgeting and resources in the project as well as coordination of communications in the project and a researcher's role, which means that project manager might be responsible for the theoretical background knowledge in the project as well as the design of the project.

Teachers are increasingly collaborating with different kinds of projects and they might be working as a project manager at the same time when working as a teacher. The skills required in projects differ from those which teachers with pedagogical qualification are used to. Usually, teachers of higher education institutions are experts in some specific subject which is embedded in their teaching topics. But project management and networking management, accountability and international communication skills, for example, are typically not present in teachers' everyday work. [7] Certified Project Manager -training was piloted to create these skills, so that Laurea UAS professionals could increase their project management competence. The integration of teaching, RDI and regional development is easiest in the work culture, which Mäki [8] has defined as combination of a collaborative work culture and "a moving mosaic work culture". This has challenged the traditional role of a teacher.

\subsection{Project managers' toolkit and core competencies}

In order to plan a quality training, enterprises should figure out what competencies they value and what are their future needs. Brandi and lannone [9] studied highest valued competencies. Today, enterprises recognize that there are soft and hard competencies. Soft competencies are communication, creativity, customer service, interpersonal competencies, knowledge and teamwork. They uncovered that the ability to apply knowledge is what enterprises will compete for. Competencies that relate directly and visibly to enterprise tasks and projects are also in high demand. Surprisingly, despite of the fact soft competencies are so highly valued, investment by enterprises in developing them is low, relative to the investments poured into hard competences.

It requires versatile competence when working in projects. The most important competencies in project work are the ability to organize, administration, communication and the ability to report. The most important thing beside these, is to understand the goal of the project and the sharing of knowledge between and inside projects. [10]. Eventually, competences needed to follow a project through are wide. Knowledge and skills, values and attitudes as well as contacts and experiences together form the set of core competences which are necessary in every project [11].

Competence development requires flexible, learner-centered strategies, that respond to immediate business needs. Today, workplace learning includes activities that are especially informal and practice-based. For example, mentorship programs, on-the-job training and online network knowledge exchanges. Brandi and lannone [9] pointed out that the most successful types of learning is short, jobspecific, in-house and learner-centered, which addresses soft competencies. Larger enterprises are in 
a stronger position to offer training opportunities and they can also include training as part of incentive packages. Although smaller enterprises can offer flexibility. There are also some cultural differences regarding workplace learning. For example, in Germany, Ireland, Slovenia and the UK, $80 \%$ of the companies give employees time off for training and development.

The program was piloted $2016-2017$ for about 40 participants representing educated professionals as teachers and project experts to increase project management competence. It contained 9 days of contact learning, each focusing on different topics related to the project managers' work. The topics were:

- The role and principles of the project manager's work

- Managing networks

- Agile Project Management

- Challenges and solutions in a project manager's daily life

- Effectiveness through communication

- Project finances

- Integration of teaching and R\&D projects

- Toolkit for marketing and communication

- Open science

The participants of the training program engaged in creating each module by giving their feedback and defining their wishes for the content of the modules. The trainers of the modules used participatory methods and kept the learning atmosphere open for constant reciprocal discussion.

We discovered that workshops are one great way of workplace learning. According to Kaner [12], there are usually certain types of challenges in workshops. One of them is a challenge to get everyone to be active and work towards mutual goals. There are different ways to activate people, for example changing the teams people work in and creating an open environment for every opinion and discussion. It can be also challenging, if the conversation goes way of the topic or don't have any specific goal. There are ways to make workshops functional. It requires an experienced facilitator, who makes a tight schedule and manages themes so that goals will be achieved.

One of the first topics in the training program was network management, which was seen as an important skill in project managers' work. Networks between people play an essential role in creating new ideas and projects as project partners create a network in which the roles of participants are built according to the targets. The project manager benefits from knowing how to lead networks and how to get added value from the network. Agility was also seen as an important ability for the project manager. Comparing to the traditional project management, agile approach helps for example in organizing meetings effectively and planning iteratively with a smaller set of requirements. Solutions to the challenges seemed to be also an important topic in the training: participants viewed typical challenging situations and co-created solutions for example to the situation of having too few resources working on too many projects at the same time. [7]

Communication and marketing were also part of the training program as communication, oral and written expression are the most needed skills to be in touch with project consortium and beneficiaries. A project manager needs to be both a clear communicator and a good marketer. Otherwise the project manager needs someone else to take care of these tasks to make sure that project consortium knows how to fulfill project goals. Integration of RDI and teaching is essential for Laurea UAS's pedagogical approach Learning by Developing. Lecturers as project managers have to create pedagogical approaches to their projects in order to integrate bachelor and master level students and projects. Training program offered tools for that. We consider the good management as the relevant topic to renew the teachers' work. [7]

There is a need for management and leadership activities that arise from the strategic choices. On the other hand, there is a huge need for the teachers, to save their freedom to decide the methods how they work and how to create new competence. We have a challenge in management and leadership when the freedom and the strategic goals are set parallel. [13]. The leadership culture has become more employee centric. The managers and directors are rather coaches and enablers than commanders and controllers. The meaning of leadership is to enable the best possible environment to work [14]. Project management training program deals with leadership issues as well. In academic 
research, there is also a need for higher efficiency, and the impact of the research is becoming more and more important in the future. We found out that by introducing new kinds of concepts for increasing competence in academic research projects, we can tackle both of the challenges. In companies' product and service development, there are many parameters to be improved, and one of those is time-to-market. If companies can introduce products and services faster than their competitors, they will get competitive advantage.

Companies are using different methods in order to introduce the right products/services into customers. Those methods include, for example, agile product development, lead production and product development. Similar methods can also be used in research projects in the academic environment. We wanted to introduce these methods also to the project managers' toolkit and their way of working.

\section{METHODOLOGY}

The research questions were: Which competencies project managers feel they need to learn most? What sort of content in project manager training program would best endorse the development of project management competencies? How participatory learning methods used in training could motivate participants?

Around four participants were interviewed after every training module in order to clarify the efficiency of each module and to figure out how participatory learning methods could help project managers to develop their competence. The total number of research participants was 25 . The interviewees were chosen randomly from the list of the participants. Every respondent was interviewed just once with predefined questions. The questions were same to all the interviewed participants. The goal of the interviews was to gather information about internal efficiency of project manager training. The secondary objective was to get information about the usefulness of the participatory methods.

Every training session contained innovative participatory methods, which were chosen with the speakers. The effectiveness of the methods were monitored during each training session. The aim was to create diverse and interactive project manager training. It was significant, that the opinions of the participants influenced in planning the tools and working methods in the following training session. It was important to develop the quality of the project manager training, which would give new competence to participants. It would have not been possible without continuous development and feedback from the participants.

\section{RESULTS}

The findings of the interviews are presented below.

\subsection{The competence is growing in collective distribution}

The results of the interviews showed that workplace learning is a complex but fruitful thing to organize. Participants saw that the most important thing in the project manager training program was networking with other colleagues who are involved with the projects as well. Most of them also thought, that having constructive dialogues with others helped them to learn and achieve personal learning goals. The interviewees said, that it didn't feel so important to study theory in the beginning of the training sessions. They still felt that a short and a compact introduction was in place before going further with the topics. Some of them suggested that it would be a good idea to send some theory to participants beforehand.

The themes of the training that the interviewees commented to be the most significant prior to their competence, were project-finance and project-communications. They also stated that challenges in projects and in project networking were important themes in the training. Some of the interviewees felt that it would have been necessary to go deeper into the subjects. Still, some of them thought that it was enough to process the themes very practically in groups with case-exercises. The interviews showed also that it is challenging that problems in different projects, for example in project-finance, can be very differently handled. Nevertheless, the participants commented, that it was significant to hear about different kinds of projects, related to their competence.

One notable issue in project-communications was that the respondents wished to get some organizational-level guidelines, how it would be appropriate to communicate about the progress of 
their projects. Furthermore, they wished some ethical discussion and reflection on projectcommunication. According to the interviewees, it was very important to get familiar with different communication methods in the training. They felt it was very useful for their daily work. The respondents also mentioned, that it was important, that the exercises were related to Laurea UAS context. Then it was possible to implement new skills to daily work at once.

One interviewee felt, that there should have been more support to the basics of project work. Still, there were lots of comments that showed the participants learned new competencies to use in their daily work. This is illustrated by the following comment from one respondent:" This training really helped me to deal with the financial issues of my project." Some of the participants have been working at Laurea UAS for over 10 years and many of them in different projects. They thought that the best result of the training was the conversation about connection of the project work and teaching.

The ensemble of the training raised biseptate opinions. Some of the participants felt there was content that was axiomatic. They didn't feel that participating in the training was useless, but hoped for more careful grouping in the case-exercises. For example, one interviewee stated:" I feel that I have these things under control, but I think it was very motivating to debate with others". Instead, some of the participants commented, that they were not familiar with the Research and Development department, which is in charge of organizing the training, and they appreciated to expand their network inside Laurea UAS. One interviewee said:" I really benefitted from the training, because I am a teacher and would not hear about the projects in Laurea's Research and Development department otherwise".

\subsection{Practical guidelines support working in projects}

Many of the interviewees saw, that the most important part of the training was the assembly of the people who work in projects at Laurea UAS. Some of the participants commented, it was really valuable to discuss things on a practical level. Few of them thought they didn't get any fresh vision to their work. Yet, they thought the conversations were interesting and they liked the fact that the trainers work at Laurea UAS themselves. As one interviewee said:" I don't think I got new things to my work from this, but the training was high-quality and I think, that everybody got something from it, considering that there were people with very different backgrounds."

Another characteristic that the respondents considered important was the practical tips related to different stages in project management. As one interviewee said: "The practical guidelines were the best offering and those I plan to take advantage of. I also got contacts from other participants and I know now who to contact, when I need help". One respondent stated also:" It is now possible to take some things into account beforehand". Another interviewee had experienced that some of the things learned in the training, might still be subconscious. Furthermore, she is planning to try some tips right away and get back to training material later. As he said: "I would like to improve the internal communication of my project and I think I start with the speed meetings".

There are possibly many practical procedures that will implement from the training into practice of working in projects in Laurea. The respondents mentioned several things, for example: "I plan to make more contacts and just take the phone and start working for it". "I have to figure out, how to apply A3technology in my work". "I think the pre-inquiry of communications was really good. It helped me to analyze the communications of my project". "I can use the elevator speech I made in the training and the new tips on the twitter right away". "I realized, that the financial management of the project should be more precise than I have done before". "I plan to bring up the students and the possibilities of the projects for the studies when we have the next meeting with management."

\subsection{Learning by interactive problem solving in groups provide efficiency and motivation}

According to the participants, the learning methods used in the training were inspirational and versatile. Usually the training sessions started with the introduction of the theme and continued with problem solving in groups. Most of the respondents commented that the rhythm of the varied methods was appropriate. Three of them felt that there should have been more lessons and less group discussions. Other interviewees thought that by group discussions, it was possible to share experiences and problems in project management.

One interesting observation was that the fruitfulness of the group discussions depended on the formation of the groups. Some of the participants commented, that the discussions were sometimes progressing too slowly. The interviewees commented the methods as follows:" Working in groups was 
fun and motivating, I don't require more theory to the training"." It was a good combination to start with the introduction and then work with the theme in groups". One respondent suggested, that it would be good to have several facilitators helping the groups to proceed. In addition to the methods used, the interviewees brought up the importance of the introductions of the themes. As one respondent said: "The speakers of the introductions were excellent". The other one thought, that it is good to have lessons, but you need to have a good speaker to make the theme interesting. Almost every respondent felt that interactive and functional methods helped them to go deeper into the themes. It is not always necessary to plan the training session carefully. In fact, one interviewee claimed that it was important that participants did things together and thought that the method didn't matter.

New propositions for the future training sessions were asked from the participants. One of the respondent suggested, that there should be more time to group discussions and that it should be possible to change the formation of the groups at the same training session. Then it would be possible to get more active conversation, if the first group was proceeding slowly. The respondents felt, that the structure of the training sessions were good, but many of them were pondering how the good discussions and tips would go into operation. One interviewee stated:" It should be carefully considered, how all of these great instructions could be exploited in the future. Otherwise this all is pointless".

As one interviewee commented, it would be important for the future that new project managers would easily get answers to their daily challenges. Those answers could be guidelines developed in group discussions, but they should be easily found. Another challenge mentioned was that the participants of the training had very different backgrounds in working as a project manager. Some of them were managing big international projects and some didn't have a project at all at that time. That influenced in the discussions, but at the same time made the discussions multifunctional. One respondent suggested, that groups should be organized differently. Maybe there could be a different training program for new project managers and experienced ones in the future.

\section{CONCLUSIONS}

Most of the results of this research signals the training has been relevant and the expertise of the project managers has grown. Earlier project managers were supposed to practice the project management skills and competencies quite independently. There were processes, guidelines and lots of administrative and financial support offered already. Though, for some reason, the support services were not as accessible for the project managers as planned. Some supportive aspects were missing.

As the organizer of the training, we still don't know which competencies the project managers feel they need to learn most. The question may have been a bit naive. After the nine sessions about all the 40 feelings are different. Even though the project manager's work is processed well and the responsibilities and tasks are well described, the project manager's work is still different in different projects, in different partner networks, with different funding instruments and with different objectives. On the other hand, the topics of the training sessions were planned together with the participants before and during the training. None of the topics was seen irrelevant, which helps to end up with the conclusion: the chosen nine topics were the ones the project managers needed to learn - maybe even the most.

Another question asked from the participants of the training was: how participatory learning methods used in a training could motivate participants? Mostly, the combination of methodologies used in the training sessions seemed to fulfill the needs of the participants. Short introductions to the topics were appreciated, but the group working sessions were thought fun and motivating. In the future, the organizers need to pay attention to the formation of the groups to keep the discussions fruitful and motivating.

As said earlier in the paper, the participants saw that the most important thing in the project manager training program was networking with other colleagues, who are managing projects as well. Most of them also thought that having constructive dialogues with colleagues helped them to learn and achieve personal goals. There are about 80 staff members working in a project manager's role at Laurea UAS (of total 500 staff members). Most of them are working as lecturers at the same time and only acting part-time as a project manager. The peers may have been quite far away in the organizational structure: in other teams, other departments or other campuses. This can be evaluated as one of the most significant findings in this study: the need to network and get and give support 
with/from/to colleagues doing the same kind of work. The understanding of this alone makes it easy to decide to continue the project manager training.

Already in the planning phase, the objective was to keep the training practical. A strategic decision was to use Laurea's own staff members as experts and instructors in the training sessions. The practicality and the appreciation of the own personnel was seen valuable. Presenting the real challenges and cases helped the others to learn from the organization's own project processes. The practical nature must be kept as the characteristic for the next trainings, for sure.

It has been quite a remarkable investment in Laurea to organize the 9-half day- training for about $10 \%$ of its staff, but according to the findings, the spent hours and effort will be gained back in saved hours, better expertise and better well-being in the project management work. There has been made a decision that the training will continue. It will be in a different format, since many of the certified project managers like to continue educating themselves with project management issues. On the other hand, there will be fresh project managers with no experiences of the work. The training needs to be flexible and up to date. Thus, there will be arranged monthly theme sessions, where anyone interested of the theme can participate. The methods will still remain the same - the collection of introductions from the experts and co-creation methodologies in familiarizing with the issues and solving the problems. The topics will be decided based on the need of the participants. On the top of that, the mentoring program will be launched in the near future.

\section{REFERENCES}

[1] J. Rajamäki, "Learning in Higher Education by European Framework Projects. Laurea's study module: "International innovation work of information systems" IEEE Global Engineering Education Conference (EDUCON) 954 - 960, 2015.

[2] J. Thomas, T. Mengel, "Preparing project managers to deal with complexity- Advanced project management education”. International Journal of Project Management, No 26. 304-315, 2008.

[3] Learning by Developing LbD Guide. Laurea University of Applied Sciences. https://www.laurea.fi/en/document/Documents/LbD_Guide_04102011_ENG.pdf. 2011. Assessed 6th January 2017.

[4] V. Taatila, K. Raij, K. "Philosophical Review of Pragmatism as a Basis for Learning by Developing Pedagogy“. Educational Philosophy and Theory, Vol. 44 (8), p.831-844, 2012.

[5] K. Raij, "Learning by Developing in Higher Education". In the Publication Katariina Raij (ed.) Learning by Developing action model. Espoo: Grano. Laurea Publications. 2014.

[6] O. Ahonen, T. Meristö, L. Ranta \& H. Tuohimaa, "Project as a Patchwork Quilt - from Study Units to regional Development". In the Publication Katariina Raij (ed.) Learning by Developing action model. Espoo: Grano, Laurea Publications, 2014.

[7] S. Juvonen, P. Nurkka, K. Väkeväinen, "Experiences of cooperation between a higher education institution and industry and its impact on working culture" in L. Gómez Chova, I. Candel Torres, and A. López Martínez (Eds.), Proceedings of INTED2017 International Technology, Education and Development Conference 6th-8th March 2017, pp. 8632 - 8637. pp. 954-960, Valencia, Spain, 2017.

[8] K. Mäki, Opetustyön ammattilaiset ja mosaiikin mestarit. Työkulttuurit ammattikorkeakouluopettajan toiminnan kontekstina. Jyväskylä studies in business and economics 109. Jyväskylä: Jyväskylän yliopisto, 2012.

[9] U. Brandi, R. lannone, 2017. "Learning strategies for competence development in enterprises". Industrial and commercial training. Vol 49. No 1, pp.1-5, 2017.

[10] I. Ruuska, M. Vartiainen, "Critical project competences - a case study". Journal of Workplace learning. Vol 15, number 7/8, pp.307-312, 2003.

[11] T. Meristö, "Tulevaisuuden näkemisestä tulevaisuuden tekemiseen: Suomi 2020. In Prime Minister's Office. Suomi 2020: visioita kansakunnan tulevaisuudesta". Suomen tulevaisuuspoliittinen selonteko, 147-162. Prime Minister's Office Publications, 1993.

[12] S. Kaner, Facilitator's guide to participatory decision-making. John Wiley \& Sons. Incorporated, 2014. 
[13] S. Niinistö-Sivuranta, P. Nurkka, J. Lahti, "Kuka varmistaa osaamisen?" In the publication Sirén, Hannu, Hannu Kotila, and Kimmo Mäki. 21 Tapaa Tehostaa Korkeakouluopintoja. Helsinki. Haaga-Helia ammattikorkeakoulu, 2015.

[14] L. Vanhanen-Nuutinen, A. Töytäri-Nyrhinen, K. Mäki, "Ammattikorkeakoulun opetushenkilöstön osaaminen ja osaamisen kehittäminen". In the Publication L. VanhanenNuutinen, A. TöytäriNyrhinen \& K. Mäki (ed.) Kiviä ja keitaita - Ammattikorkeakoulutyö muutoksessa. Haaga-Helia. Vantaa: Multiprit, $25-29,2013$. 